\title{
Evaluation of Type A personality
}

\author{
F. Kittel, M. Kornitzer and M. Dramaix \\ Laboratoire d'Epidemiologie et de Medècine Sociale, Ecole de Santé Publique, Campus Erasme, Route de Lennik, \\ 808, 1070 Bruxelles, Belgium
}

\begin{abstract}
Summary: When we look for the criteria for causation of Type A behaviour for coronary heart disease, we lack the reproducibility, the predictability to a certain extent, a pathogenic mechanism and an animal model, all four of the eight recognized criteria for causal inference. The debate therefore is still wide open.
\end{abstract}

\section{Techniques of behaviour pattern classification}

The first method used to determine Type A behaviour was a structured interview (SI), and sound tapes used for training interviewers (Friedman \& Rosenman, 1959). Today video tapes and diagnostic indicators of Type A behaviour which show a time urgency and hostility score are also used (Friedman \& Powell, 1984). The original personality score used was divided into a full blown Type A (Type A1), a largely Type A (A2), a full blown Type B (B4) and a largely Type B (B3) with an intermediate type (AB or $\mathrm{X}$ ). Two other behavioural scores have been developed. One which is widely used is the Jenkins Activity Survey (JAS) (Jenkins et al., 1967), which is a 61 item questionnaire; and the Bortner Scale composed of 14 items (Bortner, 1969). Both these methods fail to include the total psychomotor behavioural dimension which includes the voice. Nevertheless they were both found to agree satisfactorily with the SI as used in the original collaborative group study and in our own Belgian Heart Disease Prevention Project (Kittel, 1984).

\section{Relationship of Type A behaviour pattern to coronary risk factors}

As both ourselves (Kittel et al., 1982) and others have found, there was no relationship between Type A and the classical risk factors such as age, cholesterol, blood pressure, smoking habits, body mass index and the coronary risk profile, at least when social class was taken into account.

Some other coronary risk factors have been less studied in relation to Type $A$ behaviour and merit attention. Physical fitness, defined as the workload reached on a bicycle ergometer for a heart rate of 150

\footnotetext{
Correspondence: M. Kornitzer, M.D.
}

beats per minute showed no relationship with Type A using the JAS. Leisure time activity was found to have a direct relationship with Type A behaviour; the more activity the more intense the Type $A$ behaviour. The same was found for heavy leisure time activity. Thus if physical activity confers a relative protection against coronary heart disease (CHD), Type A would be more protective than Type B (Kittel et al., 1983). With alcohol consumption, however, heavy drinkers are more Type A both amongst blue and white collar middle aged males (Kornitzer, 1985).

We have also looked at the relationship between Type A and stress, more precisely job stress (Kornitzer \& Kittel, 1986). In our pròspective physical fitness study Type A assessed by the JAS was strongly correlated with stress at work, even after controlling for socio-professional class and study level (Kittel $e t$ al., 1983).

\section{Comparison of Type A studies}

Table I summarizes all the studies of Type A behaviour to date. Four show Type $A$ to be a significant independent predictor for CHD, namely the Western Collaborative Group Study (Rosenman et al., 1975); the Framingham Study (Haynes et al., 1980); the French-Belgian Pooling Project (Kornitzer \& Lellouch, 1984) and the control group of the Belgian Heart Disease Prevention Project (Kittel, 1984).

In the control group of the Belgian Heart Disease Prevention Project no hard CHD events occurred in B4 subjects while the highest incidence of hard CHD events occurred in $A 1$ subjects. When the events in Types $B$ and $A B$ were added and compared with events in Type A, the risk of CHD in the latter was doubled. Moreover in this sub-group a positive gradient of hard events appeared with increasing quartiles of Type A scores, both by JAS and Bortner techniques. In the intervention group, on the contrary, no relationship 
Table I Type 'A' behaviour and incidence of CHD

\begin{tabular}{|c|c|c|c|c|c|c|}
\hline First author & $\operatorname{Sex}$ & Age & Study & Technique & Place & Results \\
\hline $\begin{array}{l}\text { Rosenman (1975) } \\
\text { Jenkins (1974) }\end{array}$ & $\mathbf{M}$ & $39-59$ & WCGS & $\begin{array}{l}\text { SI } \\
\text { JAS }\end{array}$ & California & $\begin{array}{l}+ \\
+\end{array}$ \\
\hline Haynes (1980) & $\mathbf{M} \& \mathbf{F}$ & $45-64$ & Framingham & Framingham Scale & Massachusetts & + \\
\hline Jouve (1980) & M & $40-59$ & EDF & Bortner Scale & Marseilles & 0 \\
\hline Reed (1982) & M & $50-65$ & HНP & JAS & Honolulu & 0 \\
\hline Shekelle (1983) & $\mathbf{M}$ & $35-57$ & MRFIT & SI & USA & $\mathbf{0}$ \\
\hline Koskenvuo (1983) & $\mathbf{M}$ & $35-64$ & FTCS & Bortner Scale & Finland & 0 \\
\hline Appels (1984) & $\mathbf{M}$ & $45-59$ & KRIS & $\begin{array}{l}\text { SI } \\
\text { JAS }\end{array}$ & Netherlands & $\begin{array}{l}0 \\
0\end{array}$ \\
\hline Kornitzer (1984) & $\mathbf{M}$ & $40-59$ & FBPP & Bortner Scale & $\begin{array}{l}\text { Belgium-Paris- } \\
\text { Marseilles }\end{array}$ & + \\
\hline Kittel (1984) & $\mathbf{M}$ & $40-59$ & $\begin{array}{l}\text { BHDPP (Control) } \\
\text { (Intervention) }\end{array}$ & $\begin{array}{l}\text { SI } \\
\text { JAS } \\
\text { JAS }\end{array}$ & Belgium & $\begin{array}{l}(+) \\
+ \\
0\end{array}$ \\
\hline Kittel (1985) & $\mathbf{M}$ & $40-55$ & PFS & JAS & Belgium & 0 \\
\hline
\end{tabular}

SI, Structured Interview; JAS, Jenkins Activity Survey; WCGS, Western Collaborative Group Study; EDF, Electricité de France Study; HHP, Honolulu Heart Project; MRFIT, Multiple Risk Factor Intervention Trial; FTCS, Finnish Twin Cohort Study; KRIS, Kaunas-Rotterdam Intervention Study; FBPP, French Belgian Pooling Project; BHDPP, Belgian Heart Disease Prevention Project; PFS, Physical Fitness Study.

was found between Type $\mathrm{A}$ by the questionnaire and the incidence of hard events. Multilogistic function analysis using the classical risk factors, socio-professional class and cultural background (Dutch/French) confirmed the presence of a predictive power of Type $A$ in terms of CHD events in the control group and its absence in the intervention group.

However, seven other studies failed to show any independent prospective relationship between type A and CHD incidence (Table I). In the Physical Fitness Study, multivariate discriminant analysis showed that smoking and serum cholesterol are predictors of the incidence of CHD whereas age, body mass index, linguistic culture and Type $A$ behaviour according to JAS are not (Kittel, 1985).

These contradictory results demonstrate that the one essential criterion for causality is missing, namely reproducibility. What is the cause of these differences? The specific features of the American culture of Type A cannot be invoked since negative results are observed in the Honolulu Heart Project (Reed \& Cohen, 1982) and MRFIT (Shekelle et al., 1983) studies and positive ones in the French-Belgian Pooling Project (Kornitzer \& Lellouch, 1984) and the Control Group of the Belgian Heart Disease Prevention Project (BHDPP) (Kittel et al., 1982). Social class cannot be the main factor, as in the intervention group of the BHDPP Type A was not a predictor even in the white collar group. The effect of intervention programmes modifying Type $\mathbf{A}$ and thereby interfer- ing with the results cannot be an explanation since in a prospective study without intervention no predictive power of Type A was found. Finally, the methods of assessment of Type A could be incriminated, but in our control group of the BHDPP, Type A by the JAS was an even better predictor than by the SI.

Our present conviction is that the psycho-social coronary risk profile is multifactorial. Apart from Type A, other risk factors such as the hostility dimension and other protective factors such as social supports have to be taken into consideration.

\section{Pathogenesis of relationship of Type A behaviour pattern and CHD}

Finally, there is the problem of pathogenesis. Some studies, essentially those using the SI, have found a correlation between Type A behaviour and the degree of coronary narrowing on angiography (Franck et al., 1978). Others, like ourselves, have not observed this relationship (Kornitzer et al., 1982). Friedman et al. (1960) observed a relation of Type A behaviour with urinary catecholamine excretion comparing 10 Type $A 1$ and 10 Type B4s. We compared 30 Type A2 and 30 Type Bs and observed no difference either in urinary catecholamine excretion or in arrhythmias on $24 \mathrm{hr}$ Holter recording in the two groups (De Backer et al., 1979). 


\section{References}

APPELS, A. (1984). Type A behaviour and risk of CHD in Holland. Biobehavioural Factors in Coronary Heart Disease. Winterscheid, June 12-15.

BORTNER, R.W. (1969). A short rating scale as a potential measure of pattern A behaviour. Journal of Chronic Diseases, 22, 87.

DE BACKER, G., KORNITZER, M., KITTEL, F., BOGAERT, M., VAN DURME, J.P., VINCKE, J., RUSTIN, R.M., DEGRE, C. \& DE SCHAEPDRYVER, A (1979). Relation between CPBP excretion of urinary catecholamines, heart rate and heart rhythm. Preventive Medicine, 85, 14.

FRANCK, K.A., HELLER, S.S. \& KORNFIELD, D.S. (1978). Type A behavior pattern and coronary angiographic findings. Journal of the American Medical Association, 240, 781.

FRIEDMAN, M. \& POWELL, L.H. (1984). The diagnosis and quantitative assessment of type A behavior: introduction and description of the videotaped structured interview. Integrative Psychiatry, July-August, 123.

FRIEDMAN, M. \& ROSENMAN, R. (1959). Association of specific overt behavior pattern with blood and cardiovascular findings. Journal of the American Medical Association, 169, 1286.

FRIEDMAN, M., ST. GEORGE, S., BYERS, S.O. \& ROSENMAN, R.H. (1960). Excretion of catecholamines, 17 - ketosteroids, 17 - hydroxycorticoids and 5 - hydroxyindole in men exhibiting - a particular behavior pattern (A) associated with high incidence of clinical coronary artery disease. Journal of Clinical Investigation, 38, 758.

HAYNES, S.G., FEINLEIB, M. \& KANNEL, W.B. (1980). The relationship of psychological factors to coronary heart disease in the Framingham study. III. Eight-year incidence of coronary heart disease. American Journal of Epidemiology, 111, 37.

JENKINS, C.D., ROSENMAN, R.H. \& FRIEDMAN, M. (1967). Development of an objective psychological test for the determination of the coronary prone behavior pattern in employed men. Journal of Chronic Diseases, 20, 371.

JENKINS, C.D., ROSENMAN, R.H. \& ZYZANSKI, S.J. (1974). Prediction of clinical coronary heart disease by a test for the coronary prone behavior pattern. New England Journal of Medicine, 290, 1271.

JOUVE, A., DRIVET-PERRIN, J., BERNET, A., BLANC, M.M., EBAGOSTI, A. \& LAURENS, M. (1980). Conditions socioprofessionnelles et personnalité du coronarien. Annales Cardiologie Angeiologie, 29/4, 223.
KITTEL, F. (1984). Approche psychosociale de la prévalence et de l'incidence des affections coronariennes. p. 154-191. Doctoral Dissertation. P.U.B. - Brussels.

KITTEL, F. (1985). Type A and social factors in relation to CHD incidence. (Abstract). European Heart Journal, 6, (Suppl 1), 6.

KITTEL, F., KORNITZER, M., DE BACKER, G., DRAMAIX, M., SOBOLSKI, J., DEGRE, S. \& DENOLIN, H. (1983). Type A in relation to job-stress, social and bioclinical variables: The Belgian Physical Fitness Study. Journal of Behavioral Medicine, 9, 37.

KITTEL, F., KORNITZER, M., DE BACKER, G., DRAMAIX, M., SOBOLSKI, J., DEGRE, S. \& DENOLIN, H. (1983). Type A in relation to job-stress, social and bioclinical variables: The Belgian Physical Fitness Study. Journal of Behavioral Medicine, 9, 37.

KORNITZER, M. (1985). Life style and the major cardiovascular disease. International Conference on Preventive Cardiology - Moscow, June 23-26.

KORNITZER, M. \& LELLOUCH, J. (1984). Assessment of type A behaviour by the Bortner scale and ischaemic heart disease. The Belgian-French Pooling Project. European Heart Journal, 5, 440.

KORNITZER, M., MAGOTTEAU, V. DEGRE, C., KITTEL, F., STREYVEN, J. \& THIEL, E. (1982). Angiographic findings and the type A pattern assessed by means of the Bortner Scale. Journal of Behavioral Medicine, 5, 313.

KOSKENVUO, M., KAPRIO, J., LANGINVAINIO, H. \& ROMO, M. (1983). Mortality in relation to coronary-prone behavior: A six year follow-up of the Bortner scale in middleaged Finnish men. Cardiovascular Diseases Epidemiological Newsletter, 34, 40.

REED, D. \& COHEN, J. (1982). Type A behavior and coronary heart disease among Japanese men in Hawaii. Circulation, 66, 945.

ROSENMAN, R.H., BRAND, R., JENKINS, C.D., FRIEDMAN, M., STRAUS, R. \& WURM, M. (1985). Coronary heart disease in the W.C.G.S. Final follow-up experience of 8.5 years. Journal of the American Medical Association, 233, 872.

SHEKELLE, R., HULLEY, S., NEATON, J., BORHANI, N., MITTLEMARK, M. \& STAMLER, J. (1983). Type A behavior and risk of coronary death in M.R.F.I.T. Cardiovascular Diseases Epidemiological Newsletter, 33, 34. 